\title{
NORM risk assessment for the Søve mining complex, Norway
}

\author{
J.E. Brown ${ }^{1}$, A. Liland ${ }^{1}$, R.S. O'Brien ${ }^{2}$ and J.C. Mora ${ }^{3}$ \\ ${ }^{1}$ Norwegian Radiation Protection Authority, P.O. Box 55, N-1332 Østeras, Norway \\ ${ }^{2}$ ARPANSA 619 Lower Plenty Road, Yallambie 3085, Australia \\ ${ }^{3}$ CIEMAT, Avda. Complutense 22, 28040 Madrid, Spain
}

\begin{abstract}
The Søve site is a disused mining complex in Telemark County, Norway, exhibiting enhanced levels of naturally occurring radionuclides from the ${ }^{238} \mathrm{U}$ and ${ }^{232} \mathrm{Th}$ decay series. The nascent General Assessment Methodology Process ('GAMP'), developed under IAEA's EMRAS II programme, has been applied at the site. The a priori fixed screening criteria were exceeded in the scenario, precipitating the requirement to undertake a more detailed assessment. The USDOE's RESRAD-OFFSITE code was employed to investigate potential changes in activity concentrations in various environmental compartments over time and the contribution of various exposure pathways to effective doses. Owing to problems associated with model parameterisation and results interpretation a simple leaching and groundwater migration compartmental model was also applied. This allowed activity concentrations in three waste compartments to be calculated with time. Furthermore, an existing external dose-rate model that correlates information on activity concentrations with depth in soil to dose rates in air above ground has been used to estimate prospective external dose-rates to humans and evaluate the efficacy of applying various remediation options.
\end{abstract}

\section{INTRODUCTION}

The 'General Assessment Methodology Process ('GAMP')', is currently under development as part of WG 2 'Reference approaches to Modelling for Management and Remediation at NORM and Legacy Sites' within IAEA's EMRAS II programme [1]. The purpose of the GAMP is to provide a general methodology for the radiological impact assessment of legacy sites and is being developed for use as a tool to assist in the design of possible remediation operations at such sites.

The Søve site is a disused mining complex in Telemark County, Norway. The area exhibits enhanced levels of naturally occurring radionuclides from the ${ }^{238} \mathrm{U}$ and ${ }^{232} \mathrm{Th}$ decay series. Although some remediation work was conducted following the closure of the mine in the mid 1960s, waste, primarily in the form of clustered lumps of processed material, has become mixed in surface layers over time. Limited dose-rate measurements in air have been made and the site has been mapped by aerial gamma ray surveys [2]. This has allowed some initial estimates concerning the range and maximal dose-rates in air to be specified and a calculation of ambient dose equivalents for the public to be carried out. However, a radiation risk assessment methodology has not been rigorously applied; nor have the longterm consequences of remediation options in relation to radionuclide contamination been explored. The GAMP has therefore been applied at this contaminated site providing not only a formal assessment of the site but also an insight into the efficacy of applying the methodology to a real situation.

The initial part of the GAMP involves problem identification, site characterisation, screening criteria (reference levels) definition and screening assessment.

\section{IDENTIFYING THE PROBLEM, SITE INVESTIGATION AND CHARACTERISATION}

There is a potential problem in terms of exposure of humans and the environment at the Søve mining complex. The exposure situation as it currently stands may be in contravention of Norwegian 


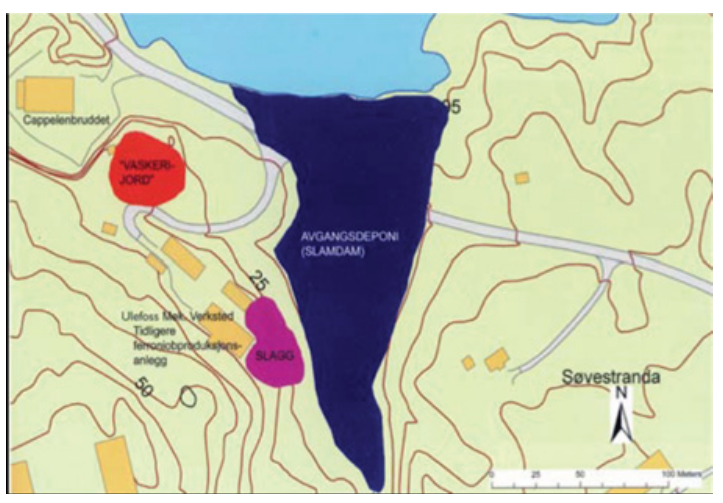

Figure 1. Contaminated areas at the Søve mining site showing the 3 specified area hazards (from [2]).

Table 1. Activity concentrations above which material becomes classified as radioactive waste in Norway.

\begin{tabular}{|l|c|c|c|c|c|}
\hline \multicolumn{7}{|c|}{ Screening values (Bq/g) } \\
\hline${ }^{238} \mathrm{U}$ & ${ }^{226} \mathrm{Ra}$ & ${ }^{210} \mathrm{~Pb}$ & Th-nat (incl. $\left.{ }^{232} \mathrm{Th}\right)$ & ${ }^{228} \mathrm{Ra}$ & ${ }^{228} \mathrm{Th}$ \\
\hline 1 & 1 & 1 & 1 & 1 & 1 \\
\hline
\end{tabular}

regulations, as defined elsewhere [2]. From a geographical perspective, three main areas can be identified from an NGI [2] report as constituting hazards:

- Sludge disposal site (slamdam) which resembles a floodplain and has a brook running through it. Mainly fine grained material $(<1 \mathrm{~mm})$ with the presence of some surficial slag lumps.

- Wash House soils (vaskerijord) - The top layer consists of sandy materials of explosion-pulverised stone (from wall-rocks) and crushed concrete. Resulted from the preliminary covering and improvement operations conducted when the mine was decommissioned. Removal of this surface material results in an increase in dose-rate.

- Slag heap (slagg)- Dumped slag was covered with carbonate sands following the cessation in mining activity. The sand is fine-grained (with low variability in texture) and, as a result, exhibits little erosive resistance. There are large erosion scars at the top of the incline caused by running water. The surface layer is comprised of decomposing vegetation material (from trees) and some rubbish.

Once objectives have been defined, screening criteria need to be set. The following guidance is given in the GAMP: "Screening criteria should be determined nationally, and expressed in practical terms, either total effective dose (or total risk), effective dose rate, or radionuclide concentrations in air, soil, water, sediment, etc." In Norway, a preliminary set of values pertaining to the level at which material is classified as radioactive waste (and thus requiring consideration under the relevant regulations), have been formulated (FOR 2010-11-01 nr 1394: Forskrift om forurensningslovens anvendelse på radioaktiv forurensning og radioaktivt avfall).

These values (Table 1) would appear to constitute suitable screening activity concentrations for use in the screening assessment.

An additional, alternative screening benchmark has been selected as being a $1 \mathrm{mSv}$ (per year) reference level to a representative person and which applies to exposure situations where individuals receive exposures - usually planned - that may be of no direct benefit to them (but the exposure situation may be of benefit to society) based on the basic recommendation of the ICRP [3]. For Søve, a limited number of measurements of activity concentration of natural decay series radionuclides have been made on samples taken from the site (Table 2). The risk quotient for this screening assessment is derived by simply dividing the measured activity by the screening benchmarks (Table 1 ). If this value (individually or as a sum over all radionuclides) exceeds 1, the screening criteria are exceeded and there 
Table 2. Measured activity concentration of some natural decay series radionuclides at the Søve site [2] and [4].

\begin{tabular}{|l|c|c|c|c|c|c|c|}
\hline & \multicolumn{7}{|c|}{ Activity Concentration (Bq/g) } \\
\hline Sample location & ${ }^{238} \mathbf{U}$ & ${ }^{226} \mathbf{R a}$ & ${ }^{210} \mathbf{P b}$ & ${ }^{232} \mathbf{T h}$ & ${ }^{228} \mathbf{R a}$ & ${ }^{228} \mathbf{T h}$ & $\mathbf{R Q}$ \\
\hline Wash House soils a & 10.9 & 12.5 & 13.6 & 15.4 & 18.8 & 19.5 & 91 \\
\hline Wash House soils b & 5.2 & 3.3 & 2.7 & 7.7 & 8.7 & 8.3 & 36 \\
\hline Wash House soils c & 1 & 0.88 & 0.89 & 1 & 0.99 & 1.1 & 6 \\
\hline Slag heap - a & n.d. & 5.4 & n.d. & n.d. & 5.2 & n.d. & $>10$ \\
\hline Slag heap - b & n.d. & 5 & n.d. & n.d. & 5.2 & n.d. & $>10$ \\
\hline Slag heap - c & n.d. & 0.04 & n.d. & n.d. & 0.04 & n.d. & 0.08 \\
\hline
\end{tabular}

n.d. - not determined.

is a requirement to progress further with a more detailed analysis. For the screening assessment based on measurement it would be typical to use the highest measured values to perform the assessment (thus ensuring conservatism). Strictly speaking this is a slight divergence from the GAMP which recommends "A screening assessment should be carried out using a conservative model that simulates the major features of the site." Since direct measurements were available and it was considered appropriate to compare these data directly with screening activity concentrations negating the requirement for a model, strict adherence to the GAMP was not considered essential for this step.

Clearly, the sum of the RQs exceeds 1 in almost all cases. The screening criteria are not met and the procedure therefore needs to move on to the next step in the methodology wherein a more realistic (intermediate) assessment is performed. A similar simplified screening assessment can be performed using dose-rate criteria and measured values for ambient dose equivalents. The RQs derived this way also exceed unity for even quite moderate occupancy times.

\section{MORE REALISTIC (INTERMEDIATE) ASSESSMENT}

The GAMP states that "If the results of the screening assessment (using clearly conservative assumptions) do not satisfy the screening criteria, then a more realistic assessment should be carried out." A more detailed assessment has been attempted through the application of the RESRADOffsite model [5]. The RESRAD-OFFSITE code provides methods for evaluating the radiological consequences to a receptor located onsite or outside the area of primary contamination. The code calculates radiological dose for the predicted radionuclide concentrations in the environment. An advective-dispersive groundwater transport sub-model has been developed to predict the transport of progeny produced in transit.

The exposure pathways for the Søve site, which are considered to be in line with GAMP guidance to develop a conceptual model, have been limit to:

- External exposure from the primary contamination - exposure time (outdoor) has been set to 0.1 corresponding to just over 1 month (ca 36 days) and it was assumed that individuals spent 0.3 years (110 days) indoors over the waste. These values have been selected to characterise the representative person as those individuals working in the building on site and might be considered very conservative as an individual would need to be working +50 hours per week 52 weeks of the years to attain these levels)

- Radon inhalation (with the same occupancy as above)

- Ingestion of fish and crustacean from the nearby lake.

Although data did not exist to define many of the required parameters specifically for the site, some parts of the problem could be specified in a site-specific manner, including the physical extent of the source and the position of receptors in relation to this. The input activity concentrations were equal to the 


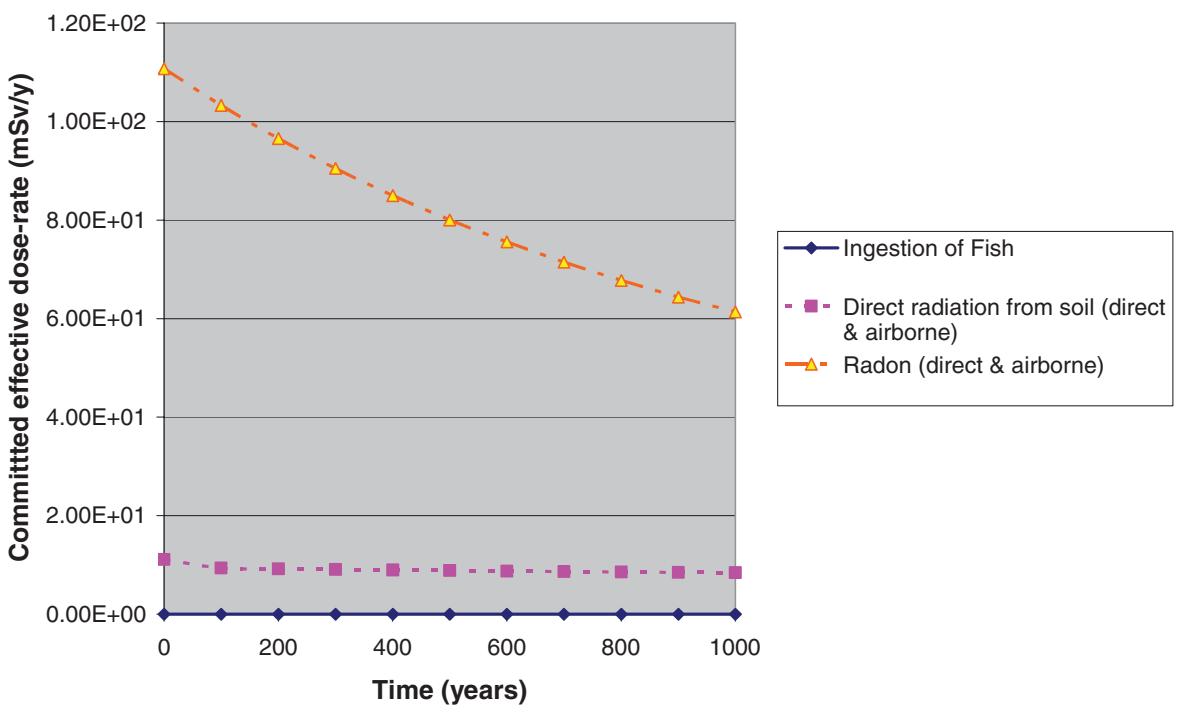

Figure 2. Annual committed dose-rates at the Søve site for the existing situation, modelled for 1000 years using RESRAD-OFFSITE.

maximum values reported for the site in NGI [2] and as reported in table 2. In addition, ${ }^{210}$ Po activity concentrations were included in the model run with values equating to those of ${ }^{210} \mathrm{~Pb}$. Site specific parameters were also defined for hydraulic conductivity and gradient, precipitation and irrigation rate and dry grain densities. For all other parameters recourse was made to RESRAD-OFFSITE defaults. Output from the model is shown in Figure 2.

In addition, models have been applied to simulate 1. Infiltration, vertical migration and groundwater flow of contaminants and 2. External dose-rates. Maps of the Søve mining site have been analysed and a transect, through the contaminated area selected with a view to producing a 2-dimensional bespoke model for the site. The rate constants between compartments in the unsaturated zone are based on information concerning infiltration rates, retardation coefficients (in turn derived from distributions coefficients), compartment depth and porosity. Rate constants between compartments in the saturated zone are a function of the Darcy velocity, retardation coefficients porosity and compartment size. The model has been parameterised as far as possible using site specific data and implemented using the model construction software ECOLEGO [6].

No rigorous validation of this model was possible - this was simply a first attempt to explore the viability of developing a bespoke model for the Søve mine. Nonetheless, a simple comparison has been made between results from the fully developed and widely tested RESRAD-Offsite model and this simplified bespoke model for selected radionuclides and time points. At time $=1000$ years, RESRAD Offsite predicts an activity concentration in the primary contamination (i.e. waste) of approximately 7 $\mathrm{Bq} \mathrm{g}^{-1226} \mathrm{Ra}$. This compares with the bespoke compartmental model value of $7.3 \mathrm{~Bq} \mathrm{~g}{ }^{-1}{ }^{226} \mathrm{Ra}$ (in 'slag heap 1' where initial conditions concerning activity concentrations were assumed to be the same as those used for the primary contamination in the RESRAD Offsite model runs). The model outputs inform us is that activity concentrations in the various hazard components remain above the screening criteria based on activity concentrations for some radionuclides even after 1000 years in the case where no remediation measures are applied.

\section{ESTABLISHING CLEANUP CRITERIA AND REMEDIATION}

GAMP guidance states that "If the decision maker decides to proceed further, either on policy grounds or because the screening criteria are not satisfied by the detailed assessment, cleanup criteria for the 


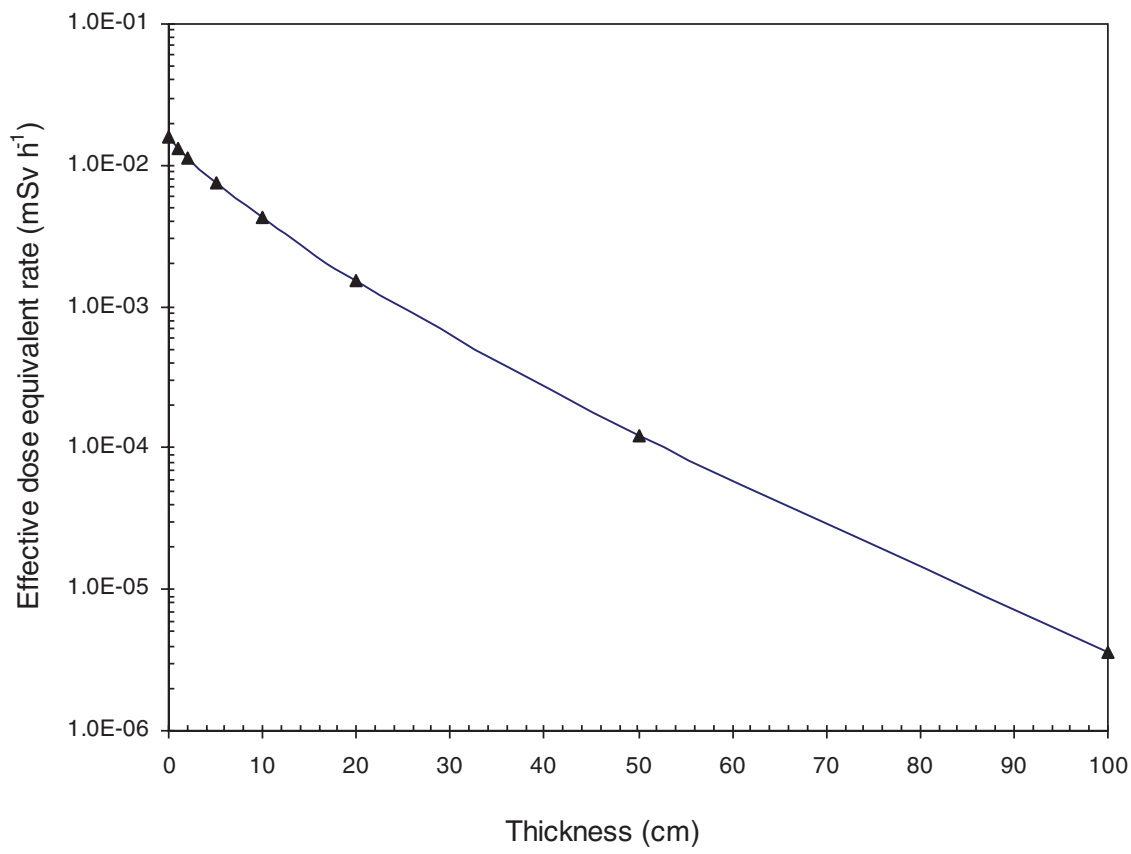

Figure 3. Influence of the thickness of a cover of clean soil on the external exposure.

remedial action need to be established." The simplest approach in setting clean-up criteria may be to re-apply the values used for the screening assessment. This is consistent with the GAMP where the consideration is aired that "The clean-up may be the same as the screening criteria" although noting that "they may also be influenced by factors other than purely radiological considerations, for example cost-effectiveness, or predicted land use, etc. In general, cleanup criteria should be chosen so as to optimise dose/risk during and after cleanup and/or remedial action." Non-radiological criteria have not been included in this particular assessment. The clean-up criteria might therefore be to:

- Remove contaminated material until the (surface) soil is below the level at which material is regulated as radioactive waste (Table 1)

- Reduce (committed, effective) doses to below the $1 \mathrm{mSv}$ (per year) reference level to a representative person based on the basic recommendation of the ICRP [3].

Three remediation options have been suggested in the report NGI [2], these being :

- Option 1 : Null alternative - leave as is

- Option 2 :Development of a local countermeasure solution that will involve removal of materials and re-disposal of the area originally allocated for the waste treatment work.

- Option 3 : Removal of radioactive waste and disposal at an approved repository.

Option 1 has already been modelled prospectively using the RESRAD-OFFSITE code in the process of applying an off the shelf model in the detailed assessment (Figure 2). The external exposure pathway associated with Option 2 has been explored in detail through the application of an External doserate model and the use of the highest activity concentration data presented in Table 2. Microshield is commercial software developed by Grove Engineering Inc. used mainly to analyze the shielding of gamma radiation, assessing personnel effective dose in different external exposure configurations. The software has been widely used in assessing effective doses in situations that can be easily reduced to simple geometries, what takes into account a great variety of real or hypothetical cases (e.g. [7]). The use of a cover of uncontaminated soil was studied using Microshield and considering several cover thickness, from 1 to $100 \mathrm{~cm}$, obtaining the results presented in the Figure 3 for the decrease in effective dose equivalent. 


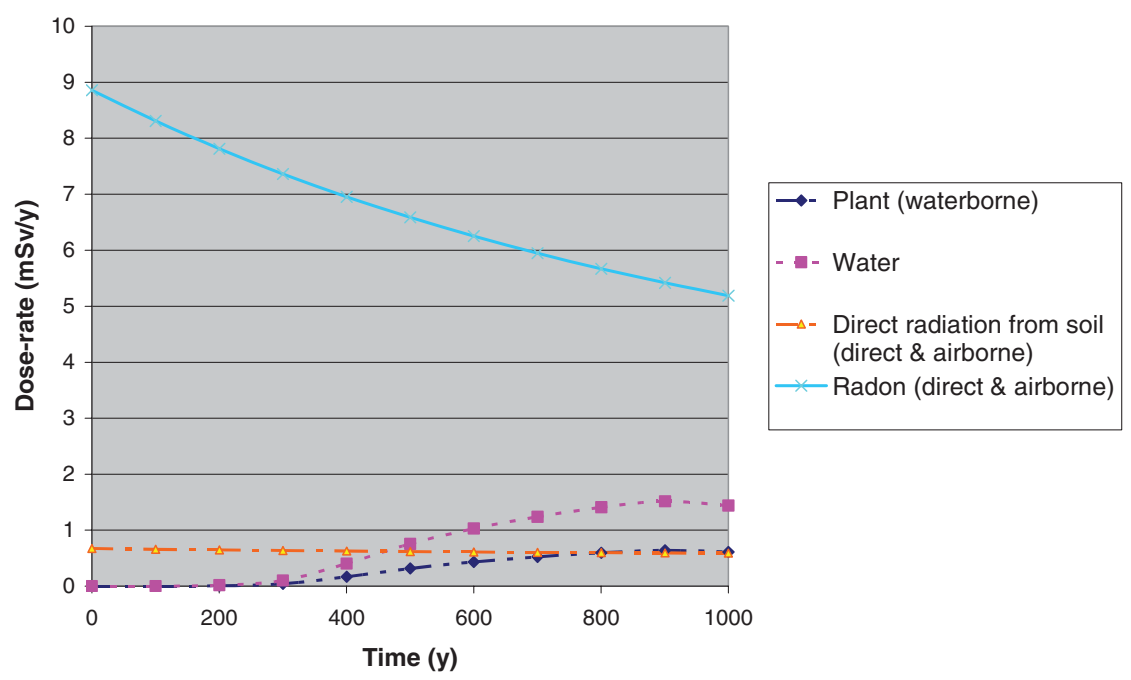

Figure 4. Doses for Scenario exploring remediation option 3 : Removal of radioactive waste to a level below the screening benchmark and opening of land to agricultural use.

Applying approximately $50 \mathrm{~cm}$ of topsoil has the effect of reducing the effective dose equivalent by a factor of approximately 100 , i.e. the exposure level arising from waste will be reduced to approximately $1 \%$ of the level without shielding to a value of around $0.1 \mu \mathrm{Sv} \mathrm{h}^{-1}$. At these dose rates, the clean-up criteria would be met even using extremely pessimistic occupancy factors. Nonetheless, this assessment provides no insight into the long-term exposure situation where erosion of the shielding layers of top soil could lead to substantially increased exposure rates in the future.

The last option (remediation involving removal and disposal) has been modified slightly so that it involves reducing the contamination source to the benchmark activity concentration presented above (Table 1), i.e. all activity concentrations $=1 \mathrm{~Bq} / \mathrm{g}$, and then using the land for agricultural production (the feasibility of which has not been evaluated) - with all available exposure pathways 'open'. A nominal cover of $0.1 \mathrm{~m}$ of clean soil has been used in line with the 'existing situation' set up. The modelling results, from the application of RESRAD-Offsite, are given in Figure 4.

The results from modelling this scenario are interesting as they show that theoretically the doserates still might exceed $1 \mathrm{mSv}$ year to a critical group owing largely to a component from radon but significantly also to contributions arising from drinking contaminated water (assumed that there is an extraction well near to the site), ingestion of crops and direct external exposures. It would seem imperative therefore to define the post-remediation use of the land so that appropriate exposure pathways can be scrutinized and secondary checks made on predicted prospective dose against established dose criteria.

\section{References}

[1] Liland, A. et al.,"The IAEA Environmental Modelling for Radiation Safety programme (EMRAS II) - new working group on Reference approaches to modelling for management and remediation at NORM and legacy sites". ICRER Conference, Hamilton Canada (2011).

[2] NGI, Kartlegging av omfang og kostnader ved eventuell senere opprydning av radioaktivt materiale ved Søve gruver; 20091927-00-14-R (In Norwegian) (2009).

[3] ICRP, Ann. ICRP 37(2007). 
[4] IFE, Radiologisk kartlegging av området rundt tidligere Søve gruver. Institutt for energiteknikk (IFE); IFE Report, IFE/KR/F - 2006/174 (In Norwegian) (2006).

[5] Yu, C., Gnanapragasam, E. Biwer, B., Cheng, J.-J., Kamboj, S., Klett, T., Zielen, A., Williams, W.A., Domotor S. and Wallo A., Radioprotection 44 (2009) 659 - 664.

[6] Avila, R. et al. ECOLEGO - A toolbox for radioecological risk assessment Proceedings of the International Conference on the Protection from the Effects of Ionizing Radiation, IAEA-CN109/80. Stockholm: International Atomic Energy Agency, 2005), pp. 229 - 232.

[7] Jong, P. and van Dijk, W. Health Physics Journal 94 (2008) 33-42. 